\title{
IN MEMORIAM PROF. MR. DR. SUDARGO GAUTAMA
}

\author{
Yu Un Oppusunggu'
}

Tanpa banyak pemberitaan, pada hari Senin 8 September 2008 di Perth, Australia telah berpulang salah seorang yuris terbaik yang pernah dimiliki oleh Indonesia, Prof. Mr. Dr. Sudargo Gautama dalam usia 80 tahun. Prof. Gautama, yang memiliki nama Tionghoa Gouw Giok Siong, sampai dengan akhir hayatnya adalah Guru Besar Luar Biasa di Fakultas Hukum Universitas Indonesia.

Jabatan akademis tersebut dimulai dari permintaan Dekan pertama FHUI, Prof. Djokosutono, kepada Dr. Gautama untuk menggantikan senior sekaligus promotor Dr. Gautama yakni Prof. G. J. Resink untuk mengajar dalam mata kuliah dan kursi "Hukum Perselisihan, teristimewa Hukum Antar Golongan". Tradisi akademis yang berlaku mengharuskan seorang Guru Besar harus memberikan pidato pengukuhan, yang merupakan suatu orasi ilmiah, secara terbuka di depan sivitas akademika sebagai tanda penerimaan jabatan yang dipercayakan kepadanya. ${ }^{2}$ Sesuai dengan tradisi itu Prof. Gautama memberikan pidato pengukuhan pada tanggal 27 September 1958 dengan judul "Hukum Antargolongan, Hukum yang Hidup!"3 Dengan demikian jabatan Guru Besar tersebut dipercayakan kepada beliau selama hampir 50 tahun! Kemudian Prof. Djokosutono meminta Prof. Gautama untuk menggantikannya sebagai Guru Besar untuk mata kuliah yang sama di Perguruan Tinggi Ilmu Kepolisian. Permintaan yang kemudian diterimanya. Sekali lagi Prof. Djokosoetono memintanya untuk jabatan yang sama, kali ini di Perguruan Tinggi Hukum Militer. Permintaan yang kemudian juga dipenuhinya. ${ }^{4}$

${ }^{1}$ Dosen Hukum Antar Tata Hukum, Bidang Studi Hukum Internasional, Fakultas Hukum Universitas Indonesia. yu_oppu@ui.edu. Penulis berterima kasih kepada Prof. Dr. Ko Swan Sik, Prof. Dr. Zulfa Djoko Basuki, Ibu Fatmah Jatim, S.H., LL.M, Ibu Lita Arijati, S.H., LL.M, Ibu Mutiara Hikmah, S.H, M.H., dan Nn. Tiurma Allagan, S.H., M.H. atas data dan informasi untuk penulisan ini.

2 Lih. Prof. Dr. (HC) R. Slamet Imam Santoso, "Guru Besar dan Pidato Pengukuhan" dalam M. Enoch Markum (Ed), Pendidikan Tinggi dalam Perspektif Sejarah dan Perkembangannya di Indonesia, Jakarta: UI Press, 2007, hal. 81-87.

${ }^{3}$ Pidato ini dicetak-ulang dan dimuat sebagai salah satu bab dari Prof. Mr. Dr. Sudargo Gautama, "Hukum Antar Tata Hukum", (Bandung: Alumni, 1996), hal. 81-135. 
Seorang Guru Besar adalah pengemban tertinggi dalam lapangan ilmu pengetahuan, karena itu, ia adalah pemegang kekuasaan tertinggi dalam ilmu pengetahuan tersebut. Tanggung jawab besar yang diemban oleh seorang Guru Besar adalah memajukan ilmu pengetahuan yang dipercayakan kepadanya dan memberikan manfaat ilmu tersebut bagi masyarakat. Melalui pidato pengukuhan yang diucapkan secara terbuka, seorang Guru Besar mengucapkan janji bahwa ia, antara lain, akan memenuhi tanggung jawabnya secara baik. Pemenuhan janji ini dapat ditagih secara terbuka. ${ }^{5}$ Sebagai seorang Guru Besar, Prof. Gautama telah menunaikan janjinya secara bertanggung jawab. Judul dari pidato pengukuhannya merupakan suatu bukti awal bahwa beliau kemudian mengembangkan ilmu pengetahuan yang dipercayakan kepadanya, yakni Hukum Perselisihan (Conflictenrecht) atau Hukum Kollisie (Collisierecht), yang juga dikenal sebagai Hukum Perdata Internasional/HPI (international privatrecht), yang mencakup hukum antargolongan atau intergentil (intergentilrecht). Sebagai pengemban ilmu tersebut, Prof. Gautama mengusulkan perubahan nama bagi Hukum Perselisihan menjadi Hukum Antar Tata Hukum (HATAH) Ekstern dan HATAH Intern, yang di dalamnya mencakup Hukum Antargolongan, Hukum Antartempat, dan Hukum Antarwaktu, untuk menggambarkan dengan tepat permasalahan hukum yang dibahas dalam cabang ilmu tersebut. ${ }^{6}$ Selanjutnya beliau menuliskan buku "Hukum Antar Golongan: Suatu Pengantar" untuk mata kuliah HATAH (Intern). ${ }^{7}$ Seri "Hukum Perdata Internasional Indonesia", yang terdiri dari delapan buku, ditulis oleh Prof. Gautama untuk mata kuliah HPI. Penulisan seri HPI ini dilakukan karena luas bidang pembahasan HPI terlalu luas untuk dijadikan hanya sebagai satu buku. Mungkin juga ada pertimbangan ekonomi yakni agar harga buku lebih terjangkau bagi mahasiswa. Oleh karena itu, Prof. Gautama secara bertahap menyusun buku seri ini ke dalam tiga jilid - Jilid I memuat bagian umum HPI, Jilid II memuat teori-teori dan prinsip-prinsip umum (règlès-gènèrales), dan Jilid II memuat bagian khusus (Besondere Teil). ${ }^{8}$ Buku-buku ini

${ }^{4}$ Lih. Prof. Mr. Dr. Sudargo Gautama, "Prof. Djokosoetono dan Hukum Antar Tata Hukum" dalam Guru Pinandita: Sumbangsih untuk Prof. Djokosoetono, S.H., (Jakarta: Lembaga Penerbitan Fakultas Ekonomi Universitas Indonesia, 2006), hal. 246.

${ }^{5}$ Santoso. Op. ('it. hal. $85-86$.

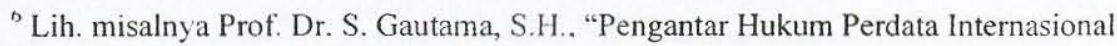
Indonesia”. (Jakarta: Binacipta. 1987), hal. 1-24.

Buku in dicetak pertama kali tahun 1957, dan terus dicetak ulang. Sampai sekarang masih tetap belum tergantikan sebagai buku wajib untuk mata kuliah Hukum Antar Tata Hukum. 
diterbitkan secara berurut, dan dengan produktifnya Prof. Gautama dalam menghasilkan karya tulis Prof. Zulfa Djoko Basuki pernah bercerita bagaimana para mahasiswa HATAH berusaha keras untuk tidak mengulang kuliah di tahun atau semester berikutnya. Karena pasti akan ada buku baru yang ditulis Prof. Gautama yang akan menjadi bahan bacaan tambahan dalam perkuliahan! Baru pada tahun 1977 Prof. Gautama menyarikan buku seri tersebut ke dalam suatu buku pengantar, yakni "Pengantar Hukum Perdata Internasional Indonesia". Buku-buku tersebut masih tetap menjadi buku pegangan wajib untuk perkuliahan HPI di FHUI bagi mahasiswa dengan program kekhususan hukum tentang hubungan transnasional.

Nama mata kuliah ini sendiri tidak diubah menjadi HATAH Ekstern, dengan pertimbangan nama HPI sudah terlanjur populer dan umum diterima. $^{9}$

Sebagai seorang yuris, Prof. Gautama sangat produktif dalam menulis artikel ilmiah, baik di jurnal nasional maupun internasional. Beliau juga sangat produktif menulis artikel-artikel hukum di media massa. Buku-buku tulisan beliau berjumlah lebih dari seratus duapuluh judul! Banyak di antara buku-buku tersebut tetap dicetak-ulang. Meski kebanyakan buku-bukunya dapat dikategorikan sebagai a no book, karena hanya merupakan kumpulan sejumlah artikel dan makalahnya, tetapi perkembangan ilmu hukum dan informasi dinamika hukum nasional maupun internasional dipaparkannya dalam tanggung jawab ilmiah, sehingga para mahasiswa dan dosen tetap dapat mempelajari perkembangan ilmu hukum, khususnya ilmu HATAH. ${ }^{10}$

${ }^{8}$ Buku I atau Jilid I membahas tentang Pengertian, Sifat dan Bidang HPI, Sejarah HPI, dan Sumber-sumber HPI. Buku II atau Jilid Kedua (Bagian Pertama) membahas tentang Sistematik HPI Indonesia, dan Titik-titik Pertalian (Aanknopingspunten). Buku III atau Jilid Kedua (Bagian Kedua) membahas tentang Penunjukan Kembali (Renvoi) dan Kualifikasi. Buku IV atau Jilid II (Bagian Ketiga), terbit terbit pertama kali tahun 1964, membahas tentang Ketertiban Umum dan Penyelundupan Hukum. Buku V atau Jilid II (Bagian Keempat), terbit pertama kali tahun 1965, membahas tentang Pilihan Hukum dan Hak-hak yang Telah Diperoleh. Buku VI atau Jilid II (Bagian Kelima), terbit pertama kali tahun 1968, membahas tentang Persoalan Pendahuluan, Penyesuaian, Timbal-balik dan Pembalasan, dan Pemakaian Hukum Asing. Buku VII atau Jilid Ketiga (Bagian Pertama), terbit pertama kali tahun 1968, membahas tentang Status Personal, Hubungan Orang Tua dan Anak, AdoPasali, Perkawinan, Hukum Harta Benda Perkawinan, Perceraian, Badan Hukum, Hukum Waris, Bentuk Formal Perbuatan Hukum, dan Benda-benda Tidak Bergerak. Buku VII Jilid Ketiga (Bagian Kedua), terbit pertama kali tahun 1969 membahas tentang Hukum Perjanjian, Juali-beli Internasional, Perbuatan Melanggar Hukum, dan Hukum Acara Perdata Internasional.

${ }^{9}$ Lih. Gautama, "Pengantar Hukum Perdata Internasional Indonesia", hal. 7.

${ }^{10}$ Misalnya Hukum Antar Tata Hukum memuat bab-bab tentang HATAH Indonesia, Perkara Tembakau Bremen, Arbitrase Dagang, dan perihal Asas Persamarataan sebagai sendi asasi HATAH; dan "Essays in Indonesian Law", (Bandung: Citra Aditya Bakti, 1993), 
Salah satu dari tridarma perguruan tinggi adalah pengabdian masyarakat. Untuk pelaksanaan darma ini Prof. Gautama, misalnya, pernah memberikan ceramah-ceramah di corong Radio Republik Indonesia (Programa III) dari tanggal 25 Mei s/d 28 September 1955. Tujuan dari ceramah-ceramah tersebut adalah untuk memberikan pengertian secara mudah dan sederhana kepada seluruh rakyat Indonesia tentang negara hukum yang sedang kita bangun. Bukanlah kebetulan jika ceramah tersebut berakhir satu hari sebelum Pemilu pertama diselenggarakan. Ceramah-ceramah tersebut kemudian dibukukan. ${ }^{11}$

Sebagai seorang mahasiswa di Fakultas Hukum dan Pengetahuan Masyarakat Universitas Indonesia, Gautama muda dikenal sebagai mahasiswa yang cerdas dan tekun. Beliau memulai kuliah di pertengahan tahun 1947 dan lulus untuk layak menyandang gelar Meester in de Rechten (Mr.) pada 18 Desember 1950. Dengan demikian, masa studi yang normalnya 4-5 tahun diselesaikannya dalam waktu tiga setengah tahun! Demikian antara lain cerita yang dikisahkan kepada penulis oleh Dr. Ko Swan Sik, juniornya di UI, yang kemudian menjadi Guru Besar Hukum Internasional di Erasmus Universiteit, Rotterdam. Disertasi Prof. Gautama yang berjudul "Segi-segi Hukum Peraturan Perkawinan Campuran" adalah disertasi hukum pertama yang ditulis dan dipertahankan dalam bahasa Indonesia. ${ }^{12}$ Disertasi yang berhasil dipertahankan di awal tahun 1955 di depan sivitas akademika UI tak pelak menyita perhatian banyak penyelidik ilmu hukum dan bahasa di Van Vollenhoven Instituut, Universitas Leiden, Belanda. Khususnya mereka yang mempelajari bahasa hukum sebagai topik disertasi. Beliau mengakui bahasa Indonesia-nya yang masih bersifat terlampau "pasaran dan penuh hollandismen" sebagai kelemahan. ${ }^{13}$ Setiap mahasiswa HATAH yang harus mempelajari buku "Hukum Antar Golongan Suatu Pengantar" tahu persis tingkat kesukaran untuk mengerti bahasa Indonesia Prof. Gautama, yang tidak jarang mengingatkan pengguna bahasa Indonesia akan Indonesia tempo doeloe.

memuat tentang Hukum Perkawinan. Pengakuan dan Pelaksanaan Putusan Asing, dan Hubungan antara Hukum dengan Pembangunan. Alumni, 1955).

"Prof. Mr. Dr. Sudargo Gautama. "Pengertian tentang Negara Hukum", (Bandung:

${ }^{12}$ Buku ini masih tetap dicetak-ulang sampai sekarang. Prof. Mr. Dr. Sudargo Gautama, "Seg1-segi Hukum Peraturan Perkawinan Campuran". (Bandung: Citra Aditya Bakti. 1996).

${ }^{13}$ Op Cit. hal. Iv-v 
Produktivitas Prof. Gautama dalam menulis sungguh menggagumkan. Apalagi jika diingat bahwa kesibukan beliau sebagai seorang advokat yang memiliki banyak klien dari dalam negeri maupun mancanegara menyita banyak waktu. Untuk tetap produktif menulis, beliau merekam ide-idenya dengan menggunakan tape recorder. Kemudian rekaman tersebut diketik oleh asistennya, untuk kemudian ia periksa. Beliau adalah salah satu dari sedikit yuris Indonesia yang menuliskan buku tentang hukum Indonesia dalam bahasa Inggris. ${ }^{14}$

Sebagai seorang advokat, beliau pernah bergabung bersama Mr. A. A. Maramis dan Mr. Iwa Kusumasumantri dalam satu kantor advokat. Nama yang disebut pertama adalah mantan anggota BPUPKI dan Menteri Keuangan pertama Republik Indonesia, sedangkan nama yang disebut terakhir adalah Rektor pertama Universitas Padjadjaran. Terakhir beliau berkantor di Prof. Mr. Dr. Sudargo Gautama and Associates yang terletak di bilangan elit ibukota, Jl. Merdeka Timur, Gambir.

Sebagai advokat beliau dalam banyak kesempatan telah membela kepentingan Republik Indonesia di berbagai forum pengadilan di mancanegara. Hal ini paling tidak dimulai dari perkara yang kemudian terkenal dengan nama The Bremen Tobacco Case, di Bremen, Republik Federal Jerman. ${ }^{15}$ Kasus ini berawal dari terbitnya Undang-Undang Nasionalisasi Perusahaan Belanda. ${ }^{16}$ Sebagai pelaksanaan dari UU tersebut, perusahaan-perusahaan milik Belanda yang ada di Indonesia dinasionalisasi dan dinyatakan sebagai milik penuh dan bebas Negara Republik Indonesia. Perkebunan tembakau milik NV Verenigde Deli-Maatschappijen dan NV Senembah-Maatschappij, keduanya adalah perusahaan Belanda, ikut di nasionalisasi dengan ganti kerugian yang akan ditetapkan kemudian. Sebagai gantinya Indonesia mendirikan Pusat Perkebunan Negara (PPN) Baru. Pemerintah kemudian menetapkan Bremen sebagai kota untuk

14 Buku-buku tersebut adalah Sudargo Gautama dan Robert Hornick, $A n$ Introduction to Indonesian Law: Unity in Diversity, pertama kali terbit tahun 1972; Prof. Mr. Dr. Sudargo Gautama, Indonesian Business Law, pertama kali terbit tahun 1995; dan Prof. Mr. Dr. Sudargo Gautama, The Commercial Laws of Indonesia, pertama kali terbit tahun 1998.

${ }^{15}$ Lih. $I$ U 159/1959, I U 201/1959, 7 Q 12/1959, 7 Q 13/1959, dan 7 Q 26/1959, Judgment of the Bremen Court of Appeal (Hanseatisches Oberlandesgericht Brement), 21 August 1959 relating to sale of Indonesian Tobacco at Bremen. Untuk ringkasan perkara ini lih. Department of Information of the Republic of Indonesia, The Bremen Tobabbo Case, Djakarta: 1960. Lih. juga Prof. Mr. Dr. Sudargo Gautama, Segi-segi Hukum Internasional pada Nasionalisasi di Indonesia: (Jakarta: Penerbitan Universitas, 1960).

16 Undang-Undang No. 86 Tahun 1958 tentang Nasionalisasi PerusahaanPerusahaan Milik Belanda di Indonesia, Lembaran Negara No. 162 Tahun 1958. 
memperdagangkan tembakau, dan membentuk Deutsch-Indonesische Tabakhandels $\mathrm{GmbH}$, suatu perusahaan patungan PPN Baru dengan sejumlah pedagang tembakau asal Bremen. Pihak Deli-Senembah menilai tindakan nasionalisasi tersebut sebagai suatu tindakan barbar dan merupakan suatu bentuk tekanan politik terkait dengan masalah Irian Barat. Oleh karena itu, ketika tembakau hendak diperdagangkan di Bremen, mereka mengajukan klaim kepemilikan, karena menurut mereka Indonesia tidak benar-benar akan memberikan ganti kerugian atau kompensasi, sehingga yang terjadi bukan nasionalisasi melainkan ekspropriasi. Kasus ini kemudian disidangkan di Landgericht, Bremen. Isu-isu hukum dalam sengketa ini menyita perhatian dunia internasional. Di bidang hukum internasional (publik) salah satu isu hukum krusial adalah apakah kompensasi bagi Deli-Senembah harus bersifat adequate, prompt, dan effective? Apakah nasionalisasi tersebut bertentangan dengan prinsip-prinsip hukum umum yang diakui oleh negara-negara (general principles of law as recognized by civilized nations)? Di bidang HPI, isu hukum krusial dari nasionalisasi tersebut adalah ketertiban umum (ordre public) dan doktrin tindakan negara (act of state doctrine). Pihak DeliSenembah diperkuat dengan dukungan sebelas orang Guru Besar, yang antara lain adalah Prof. Logemann, Prof. Lemaire, dan Prof. Kollewijn dari Universitas Leiden. Mereka bertiga pernah menjabat Guru Besar di Rechtshogeschool (yang kemudian menjelma menjadi FHUI). Prof. Logemann untuk Hukum Tata Negara dan Hukum Administrasi Negara, Prof. Kollewijn untuk Pengantar Ilmu Hukum dan kemudian Hukum Intergentiel, dan Prof. Lemaire menggantikan Prof. Kollewijn untuk mata kuliah-mata kuliah yang sama. ${ }^{17}$ Pihak Indonesia diperkuat oleh lima orang Guru Besar, yakni Prof. Dölle dan Prof. Zweigert, dan Prof. Ipsen dari Universitas Hamburg, Prof. Mr. Dr. Soekanto dan Prof. Gautama dari Universitas Indonesia. Gautama muda adalah murid Prof. Lemaire di UI. Maka terjadilah "pertarungan" antara guru lawan murid! Sengketa ini akhirnya diselesaikan melalui keputusan pengadilan banding, Oberlandesgericht, Bremen, pada tanggal 21 Agustus 1959, yang menguatkan putusan Landgericht tanggal 21 April 1959 dan 16 Juni 1959, yakni menolak gugatan pihak Deli-Senembah. Pengadilan Jerman menerima argumentasi Indonesia, yang antara lain adalah bahwa kompensasi yang bersifat adequate, prompt, dan effective tidak bisa diterapkan secara kaku.

${ }^{17}$ Informasi ini adalah sebagaimana disampaikan oleh Prof. Ko Swan Sik kepada Penulis. Tentang Prof. Logemann lih. juga sepatah kata yang ditulis oleh Prof. G. J. Resink untuk terjemahan Indonesia dari buku Logemann Over de theorie van een stellig staatsrecht, Makkatutu, SH dan Drs J. C. Pangkerego, "Tentang Teori Suatu Hukum Tata Negara Positif", (Jakarta: Ichtiar Baru-van Hoeve, 1975), hal. XIII-XVIII. 
Jika diterapkan secara kaku, maka cita-cita luhur kemerdekaan yang antara lain memperbaiki perekonomian yang terpuruk pasca-kolonialisme hanya akan sia-sia akibat terkurasnya kas negara untuk membayar kompensasi sekaligus kepada pihak Belanda. Oleh karena itu, kompensasi yang wajib dibayarkan harus memperhatikan kondisi perekonomian dan kemampuan Indonesia. Dengan demikian nasionalisasi yang dilakukan Indonesia adalah sah!

Sengketa hukum lainnya yang cukup menyita perhatian dunia ilmu hukum adalah sengketa pencabutan izin oleh Pemerintah atas investasi di Hotel Kartika Plaza. Pihak investor asal Amerika AMCO menuntut Pemerintah di forum arbitrase International Centre for Settlement of Investment Dispute (ICSID) atas pencabutan izin tersebut, dan menuntut kompensasi sebesar US\$ 17 ditambah bunga semenjak tahun 1981. Pemerintah Indonesia membentuk tim pengacara, dengan Prof. Gautama di dalamnya, untuk membela kepentingan Pemerintah. Argumentasiargumentasi hukum yang diajukan oleh tim ini berhasil untuk menyakinkan para arbitrator, sehingga Indonesia hanya perlu memberikan kompensasi sebesar US\$2,5 juta dengan bunga $6 \%$ per tahun sejak tahun $1990 !^{18} \mathrm{Di}$ atas lahan hotel tersebut yang beralamat Jl. Moh. Husni Thamrin No. 9 tersebut kini sedang dibangun Gedung UOB Plaza.

Ketika pada akhir dekade 70-an harga minyak dunia melambung, OPEC dan negara-negara anggotanya digugat di depan US District Court for the Central District of California, Los Angeles, oleh International Association of Machinists and Aerospace Workers (IAM). ${ }^{19}$ IAM merupakan suatu serikat buruh yang merasa dirugikan oleh tingginya harga minyak di Amerika Serikat, dan berpendapat bahwa hal tersebut ulah OPEC dan negara-negara anggotanya. Untuk membela kepentingannya, negara-negara OPEC dan OPEC membentuk tim yang terdiri dari para ahli hukum. Menteri Pertambangan ketika itu Prof. Dr. Subroto dan Dirjen Migas, Ir. Wijarso, menunjuk Prof. Gautama untuk terlibat dalam tim tersebut. Beliau menyarankan agar tidak dilakukan pembelaan langsung di muka pengadilan, karena berdasarkan teori imunitas negara yang berdaulat tidak dapat digugat di hadapan pengadilan negara lain. Tetapi untuk menjaga kepentingan Indonesia, beliau menyarankan agar Indonesia-US Business Committee,

${ }^{18}$ Lih. "Putusan Terakhir Pusat Arbitrase Mengenai Perkara Hotel Kartika Plaza" dalam Prof. Mr. Dr. Sudargo Gautama Arbitrase Bank Dunia tentang Penanaman Modal Asing di Indonesia dan Jurisprudensi Indonesia dalam Perkara Hukum Perdata, (Bandung: Alumni, 1994), hal. 1-67.

19 Lih. Prof. Mr. Dr. Sudargo Gautama, "Soal-soal Aktual Hukum Perdata Internasional", (Bandung: Alumni, 1981), hal. 173-208. 
yang merupakan bagian dari KADIN, mengajukan pembelaan-pembelaan secara tidak langsung untuk membukakan mata hakim tentang posisi Indonesia dan negara-negara anggota OPEC. Strategi ini berhasil, karena tindakan-tindakan negara-negara anggota OPEC tersebut dinyatakan tidak dapat diadili oleh US District Court. Upaya banding dari IAM ternyata ke US Court of Appeals for the Ninth Circuit hanya menghasilkan putusan yang menguatkan putusan US District Court.

Dalam banyak perkara yang melibatkan Pemerintah Indonesia sebagai tergugat Prof. Gautama juga dilibatkan sebagai saksi ahli. Dalam perkara Pertamina lawan Kartika Thahir di pengadilan Singapura, Prof. Gautama tampil sebagai saksi ahli untuk membela kepentingan Indonesia. ${ }^{20}$ Terakhir beliau memberikan kesaksian untuk Indonesia dalam perkara Karaha Bodas, yang putusannya beliau kecam tidak berdasarkan hukum Indonesia sebagaimana dinyatakan oleh para arbitrator. Kecaman tersebut beliau bukukan dalam "Arbitrase Luar Negeri dan Pemakaian Hukum Indonesia" (2004).

Beratnya tugas yang dipercayakan sebagai saksi ahli untuk membela kepentingan Indonesia dalam berbagai forum pengadilan internasional kerap beliau ceritakan kepada para asisten dan mahasiswanya dengan mengatakan "The loneliest place in the world is at the witness stand".

Kepakaran ilmu hukum yang beliau miliki juga diakui oleh dunia internasional. Salah satu bentuk pengakuan tersebut adalah beliau menjadi Guru Besar Tamu (gasthoogleraar) pada tahun 1967 dan 1968 di Universitas Amsterdam, di Sydney University Law School (1970), dan di National University of Singapore. Atas pertimbangan kepakaran ilmu hukum yang dimilikinya juga Prof. Gautama menjadi orang Indonesia pertama yang terdaftar sebagai Arbiter di ICSID, WIPO (World Intellectual Property Organization) juga mencantumkannya sebagai Arbiter terdaftar.

Pada tahun 1967 Pemerintah menunjuk Prof. Resink untuk mengetuai delegasi Indonesia ke Konferensi Den Haag untuk Hukum Perdata Internasional, di mana Indonesia berpartisipasi sebagai pengamat (observer). Sebagai anggota dari delegasi Indonesia adalah Prof. Gautama dan Dr. Ko Swan Sik. Tahun berikutnya, Prof. Gautama menjadi ketua delegasi Indonesia, dengan anggota alm. Teuke Moh. Radhie, Dr. Ko Swan Sik dan Dr. Mathilde Sumampouw. ${ }^{21}$ Dua nama terakhir adalah mantan dosen di

${ }^{20}$ Terkait dengan kasus Pertamina lawan Kartika Thahir, beliau menulis dua buku yakni Perkara Pertamina lawan Kartika Thahir Cs. dan Jurisprudensi Indonesia Mengenai Hukum Perdata Internasional, Bandung: Alumni 1993, dan Putusan Banding dalam Perkara Pertamina lawan Kartika Thahir, (Bandung: Citra Aditya Bakti), 1995. 
FHUI dan ketika itu sudah bekerja di Asser Intituut, Belanda. Pemerintah kemudian menunjuk Prof. Gautama untuk menjadi Ketua Tim Antardepartemen untuk Penyusunan Rancangan Undang-Undang Hukum Perdata Internasional. Tugas tersebut tuntas dilaksanakan, dan hasilnya dilokakaryakan pada 29-30 September 1983 oleh Badan Pembinaan Hukum Nasional. ${ }^{22}$ Sangat disayangkan meski intensitas hubungan transnasional semakin tinggi RUU tersebut tidak pernah dibahas secara serius untuk menjadi UU. Akhirnya Indonesia masih terus bergantung pada peraturan peninggalan zaman kolonial, yakni Algemeene Bepalingen van Wetgeving (AB), untuk mengatur permasalahan-permasalahan HPI.

Sebagai seorang Guru Besar, Prof. Gautama memiliki sejumlah asisten. Di antara mereka adalah almh. Ny. S. J. Hanifah Wiknjosastro, S.H., yang menjadi dekan wanita pertama di FHUI periode 1978-1984, dan alm. Prof. Charles Himawan, S.H., LL.M, SJD., dekan FHUI periode 1990-1993. Saat ini kursi Guru Besar Hukum Antar Tata Hukum yang pernah dipercayakan kepada beliau diberikan kepada mantan asistennya Prof. Dr. Zulfa Djoko Basuki, S.H., M.H.

Cerita di atas hanya sebagian kecil dari kiprah dan perjuangan beliau sebagai seorang yuris dan advokat kaliber internasional untuk kepentingan bangsa dan negara Indonesia, ilmu hukum, dan almamaternya. Harimau mati meninggalkan belang, Sang Profesor pergi meninggalkan karya dan tauladan. Selamat jalan Prof.! Hartelijke dank voor uw leer zame lessen.

${ }^{21}$ Lih. Prof. Mr. Dr. Sudargo Gautama, "Kapita Selekta Hukum Perdata Internasional", (Bandung: Alumni, 1983), hal. 13.

${ }^{22}$ Lih. Lokakarya Hukum Perdata Internasional, Jakarta: BPHN, 1984. 


\section{Daftar Pustaka}

Imam Santoso, R. Slamet. "Guru Besar dan Pidato Pengukuhan" dalam M. Enoch Markum (Ed), Pendidikan Tinggi dalam Perspektif Sejarah dan Perkembangannya di Indonesia, Jakarta: UI Press, 2007, hal. 81-87.

Gautama, Sudargo. "Prof. Djokosoetono dan Hukum Antar Tata Hukum" dalam Guru Pinandita: Sumbangsih untuk Prof. Djokosoetono, SH, Jakarta: Lembaga Penerbitan Fakultas Ekonomi Universitas Indonesia, 2006.

. Pengantar Hukum Perdata Internasional Indonesia, Jakarta: Binacipta, 1987.

. Pengertian tentang Negara Hukum, Bandung: Alumni, 1955.

. Segi-segi Hukum Peraturan Perkawinan Campuran, Bandung: Citra Aditya Bakti, 1996.

- Soal-soal Aktual Hukum Perdata Internasional, Bandung: Alumni, 1981. 1983.

. Capita Selekta Hukum Perdata Internasional, Bandung: Alumni,

dan Robert Hornick, An Introduction to Indonesian Law: Unity in Diversity, pertama kali terbit tahun 1972; Prof. Mr. Dr. Sudargo Gautama, Indonesian Business Law, pertama kali terbit tahun 1995; dan Prof. Mr. Dr. Sudargo Gautama, The Commercial Laws of Indonesia, pertama kali terbit tahun 1998.

Lokakarya Hukum Perdata Internasional, Jakarta: BPHN, 1984.

"Putusan Terakhir Pusat Arbitrase Mengenai Perkara Hotel Kartika Plaza" dalam Prof. Mr. Dr. Sudargo Gautama Arbitrase Bank Dunia tentang Penanaman Modal Asing di Indonesia dan Jurisprudensi Indonesia dalam Perkara Hukum Perdata, Bandung: Alumni, 1994.

Undang-Undang No. 86 Tahun 1958 tentang Nasionalisasi PerusahaanPerusahaan Milik Belanda di Indonesia, Lembaran Negara No. 162 Tahun 1958. 